\title{
Cancer risk analysis and assessment of trihalomethanes in drinking water
}

Published online: 22 February 2006

(C) Springer-Verlag 2006

\begin{abstract}
This study conducts risk assessment for an array of health effects that may result from exposure to disinfection by-products (DBPs). An analysis of the relationship between exposure and health-related outcomes is conducted. The trihalomethanes (THMs) species have been verified as the principal DBPs in the drinking water disinfection process. The data used in this study was collected from the Taiwan Water Corporation (TWC) from 1998 to 2002. Statistical analysis, multistage of Benchmark model, Monte Carlo simulation (MCS) and sensitive analysis were used to estimate the cancer risk analysis and assessment. This study included the statistical data analysis, epidemiology investigation and cancer risk assessment of THMs species in drinking water in Taiwan. It is more significant to establish an assessment procedure for the decision making in policy of drinking water safety predominantly.
\end{abstract}

Keywords DBPs - Monte Carlo simulation ·

Multistage of benchmark model $\cdot$ Sensitive analysis

\section{Introduction}

Chlorination has been the major, economical and effective drinking water disinfection strategy from microorganisms. This disinfection process may induce serious waterborne infectious diseases dangerous to public health. Research consequence of Rook (1974) and

H.-K. Lee · W.-M. Chen

Department of Water Source Engineering,

100, Wnehwa Road, Seatwen, Taichung, 407, Taiwan, ROC

Y.-Y. Yeh $(\bowtie)$

Graduate Institute of Civil and Hydraulic Engineering,

100, Wnehwa Road, Seatwen, Taichung,

407, Taiwan, ROC

E-mail: yyyeh@fcu.edu.tw

Tel.: + 886-4-24517250

Fax: + 886-4-24513797
Bellar et al. (1974) exhibited that disinfection by-products (DBPs) were produced in the disinfection process. Nowadays, such disinfection process is most adopted in drinking water treatment commonly (Houston 1913; Yang et al. 1998; Hsu et al. 2001).

Disinfection by-products are defined as hazardous materials with carcinogenic risk by Taiwan USEPA. Animal and epidemiology study evaluations have shown that developmental toxicity and adverse effects are the main potential risks to humans. The result from animal studies demonstrated evidence of liver, kidney, intestinal tumor genesis, urinary bladder, rectum and colon cancer (Morris et al. 1992; Doyle et al. 1997; Cantor et al. 1998) and some associated effects of intrauterine growth and retardation (Kramer et al. 1992). Low birth weight, small for gestational age, central nervous system defects, oral cleft defects and cardiac defects (Bove et al. 1995), retarded fetal growth (Gallagher et al. 1998) and spontaneous abortion (Waller et al. 1998) that are caused by disinfected water. Epidemiologic studies were conducted that examined the possible associations between consumption of chlorinated drinking water and cancer mortality, risk or incidence (Page et al. 1976; Cantor et al. 1978, 1987, 1998; Yang et al. 1998, 2000). The results suggest a positive association between consumption of chlorinating drinking water and cancer of the rectum, lung, bladder and kidney (Yang et al. 1996).

This study has been carried out from 1998-2002, in order to develop risk assessment and management for THMs species in drinking water for the purpose of preserving a safe environment and protecting human health in Taiwan. Risk assessment is a systematic, analytical method used to determine the probability of adverse effects. The purpose of this study conferred the risk assessment to process the derived THMs species in the drinking water of Taiwan. By following the estimation procedure of risk assessment, the outcomes will interpret the condition of the level of impact by THM species. The consequence may be a good decision-making process for risk management in the drinking water. 


\section{Methods}

The risk assessment paradigm was developed by the US NRC (National Research Council 1983) to evaluate the procedures of framework. It contained hazard identification, dose-response assessment, exposure assessment and risk characterization, mainly.

\subsection{THMs species data in Taiwan since 1998-2002}

This study assumed and divided the geographical distribution of Taiwan into five parts (northern, midland, southern, eastern and external islands). Official Data obtained from Taiwan Water Corporation (TWC) since 1998 to 2002. There are 35, 45 and 13 water treatment plants and 25, 52 and 54 supply systems in Northern, Midland and Eastern regions. 30 water treatment plants and 45 supply systems in Southern and External islands regions, respectively. The monitoring stations examined the temperature, $\mathrm{pH}$ per month and THMs species for three months. Four thousand nine hundred and forty water quality monitoring data are obtained from those monitoring stations that was published in the annual TWC subscriber drinking water reports.
2.2 Cancer risk analysis and assessment

\subsubsection{Hazard identification of THMs species}

Hazard identification involves a qualitative assessment of the presence of, and the degree of hazard that an agent could have on potential receptors. USEPA has developed a scheme that contains two broad categories of sufficient and insufficient evidence in Table 1. Hossein (1995) defined THM species as TCM, BDCM, DBCM and TBM, respectively. Animal and epidemiology studies exhibited THMs species by considered weight of evidence in EPA reports on cancer guideline descriptions about Group B2 as TCM, BDCM, DBCM and Group C is TBM (USEPA 1999), respectively.

\subsubsection{Dose-response assessment}

Dose-response relationships are then used to quantitatively evaluate the toxicity information, and to characterize the relationship between dose of the contaminant administered or received and the incidence of adverse effects on the exposed population. Specially, the purpose of the assessment developed for the risk management ensures the safety and offers procedures to control the quality of drinking water.
Table 1 Basic processes involved in USEPA carcinogenesis
Table 2 Animal experimental carcinogenic data derived from THMs species

\begin{tabular}{|c|c|c|}
\hline Group A & Human carcinogen & $\begin{array}{l}\text { Sufficient human evidence for causal } \\
\text { association between exposure and cancer }\end{array}$ \\
\hline Group B1 & Probable human & Limited evidence in humans \\
\hline Group B2 & Probable human & $\begin{array}{l}\text { Inadequate evidence in humans and } \\
\text { sufficient evidence in animals }\end{array}$ \\
\hline Group $C$ & Possible human carcinogen & Limited evidence in animals \\
\hline Group D & $\begin{array}{l}\text { Not classifiable as to } \\
\text { human carcinogenicity }\end{array}$ & Inadequate evidence in animals \\
\hline Group E & $\begin{array}{l}\text { No evidence of carcinogenicity } \\
\text { in humans }\end{array}$ & $\begin{array}{l}\text { At least two adequate animal tests or } \\
\text { both negative epidemiology and } \\
\text { animal studies }\end{array}$ \\
\hline
\end{tabular}

\begin{tabular}{|c|c|c|c|c|c|}
\hline \multirow[t]{2}{*}{ Chemicals } & \multirow[t]{2}{*}{ Data set } & \multicolumn{3}{|l|}{ Data values } & \multirow[t]{2}{*}{ Reference } \\
\hline & & Dose $(\mathrm{mg} / \mathrm{kg} /$ day $)$ & $N$ & Incidence & \\
\hline TCM & $\begin{array}{l}\text { Moderate or marked fatty } \\
\text { cysts in males plus females }\end{array}$ & $\begin{array}{l}0 \\
15 \\
30 \\
25 \\
50\end{array}$ & $\begin{array}{l}27 \\
15 \\
15 \\
50 \\
50\end{array}$ & $\begin{array}{l}1 \\
9 \\
13 \\
1 \\
8\end{array}$ & Heywood et al. (1979) \\
\hline BDCM & B6C3F1 mice, male & $\begin{array}{l}0 \\
25 \\
50\end{array}$ & $\begin{array}{l}46 \\
49 \\
50\end{array}$ & $\begin{array}{l}1 \\
2 \\
9\end{array}$ & NTP (1987) \\
\hline DBCM & Mouse/B6C3F1, female & $\begin{array}{l}0 \\
50 \\
100\end{array}$ & $\begin{array}{l}50 \\
49 \\
50\end{array}$ & $\begin{array}{l}6 \\
10 \\
19\end{array}$ & NTP (1985) \\
\hline TBM & F344/N rat, female & $\begin{array}{l}0 \\
25 \\
50\end{array}$ & $\begin{array}{l}50 \\
50 \\
50\end{array}$ & $\begin{array}{l}0 \\
1 \\
8\end{array}$ & NTP (1988) \\
\hline
\end{tabular}


In the dose-response assessment step, the goal determined the relationships between the route, dose, frequency and duration of exposure conditions and the health that effect chemical hazards. Additionally, apply the uncertainty or safety factors and mathematical model may an approach by USEPA.

Benchmark model (USEPA http://www.epa.gov/ ncea, 2003b) supported the assessment tool focused on the low-dose in the animal experiment that may cause an observed adverse influence. Generally, the adverse effects included reproductive, developmental toxicity or mortality phenomenon etc.

In this study, we adopted the USEPA risk assessment guidance (1986) and the reference data (Table 2) of animal studies from Integrated Risk Information System (IRIS, 2003) to process the BMD/BMDL value of THM species mathematically. BMD/DMDL value can interpret the toxicity information of THM species in the lowdose level.

\subsubsection{Exposure assessment}

Exposure is defined as human contact with THM species through different pathways. Referring to the exposure factor data handbook (USEPA 1997), USEPA risk

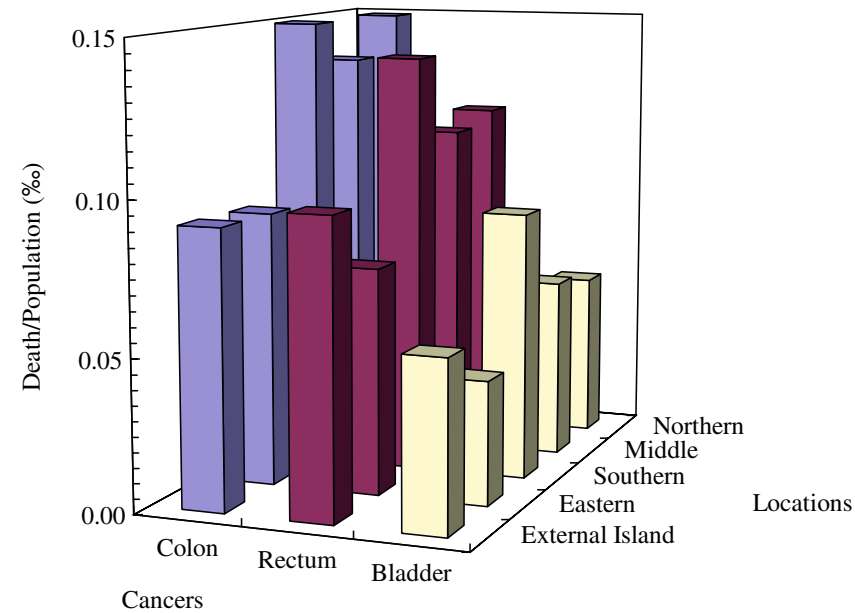

Fig. 1 Announced consequences in death of colon, rectum and bladder cancers by DOH of Taiwan

assessment guidance for superfund Volume-Human Health Evaluation Manual (USEPA 1989), and Risk Assessment Information System (RAIS 2003a) assumed the pathways to reasonable maximum exposure (RME) to THM species as ingestion, inhalation and dermal intake, evaluated based on chronic daily intake (CDI).

Table 3 References data and formula for exposure assessment

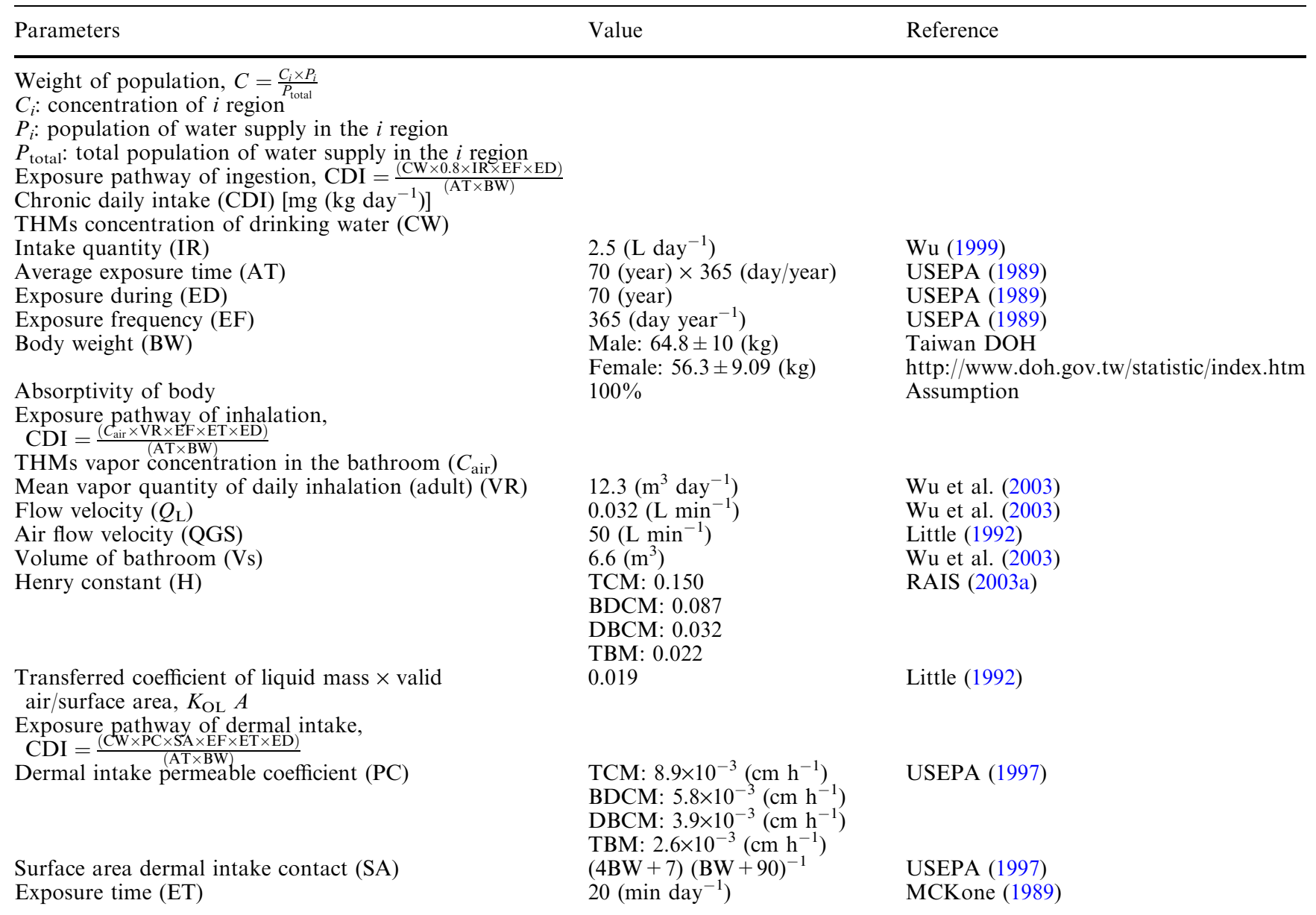




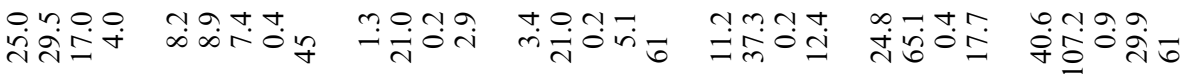

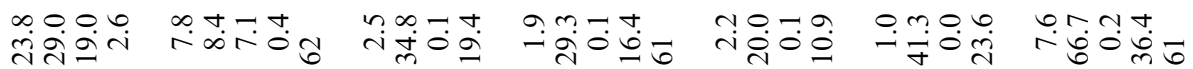

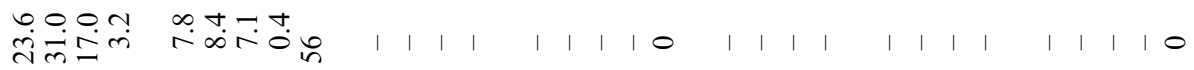

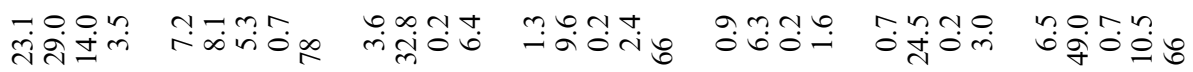
भim.

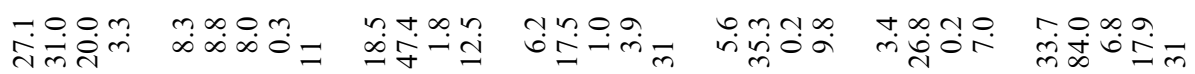

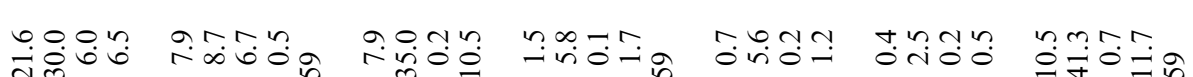

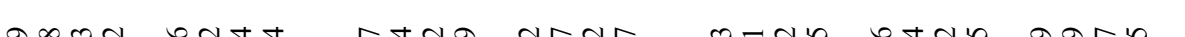

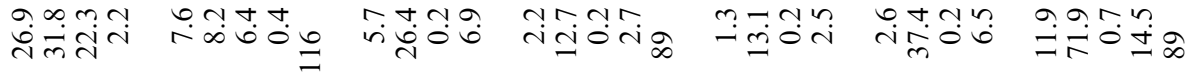

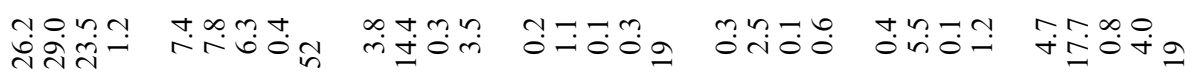

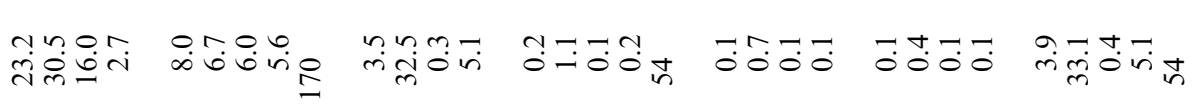

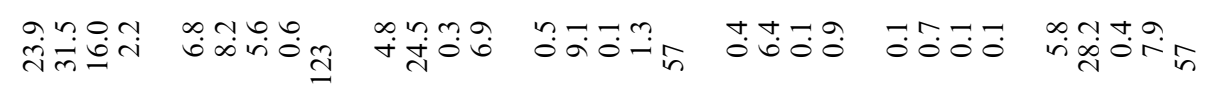

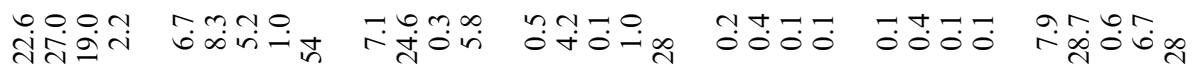

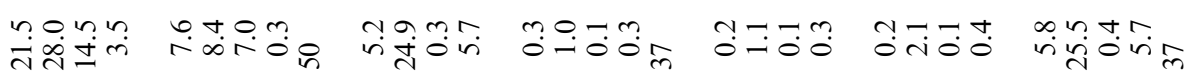

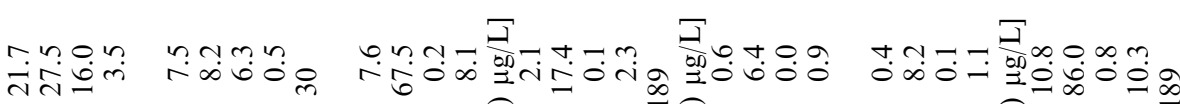
$\overrightarrow{\mathrm{N}} \hat{\mathrm{N}}$

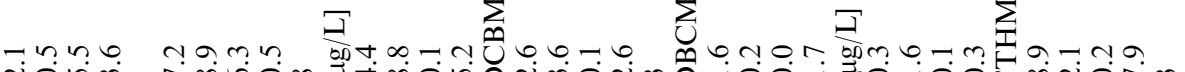

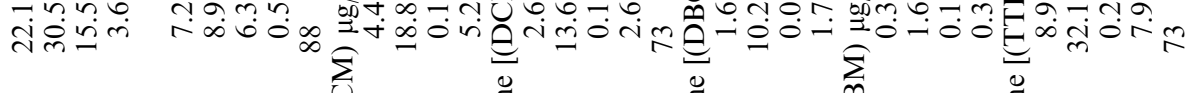

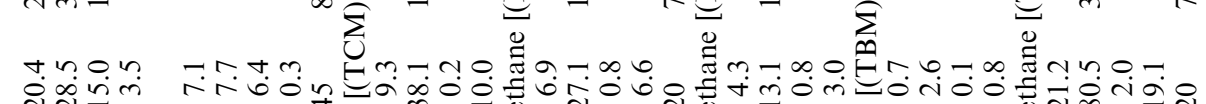
तें山m $\underbrace{0}_{0}$ 
For many drinking water DBPs, the potential for exposure and uptake occurs by ingestion but also through dermal absorption or inhalation (Lee et al. 2004). Since 1990, scientists proposed that inhalation and dermal absorption were considered in the risk assessment of drinking water (Jo et al. 1990; Maxwell et al. 1991; Weisel and Jo 1996; Weisel et al. 1999; Lin and Hoang 2000).

Moreover, the study assumed the behaviors of "drinking water", "take a shower", and "skin contact in the shower" represent the exposure pathways of ingestion, inhalation and dermal intake simplistically (Dan 2003; Chen 2003). The mathematic model by Little (1992) exhibited THM species concentration within the air was influenced by many parameters adopted to evaluate the concentration in the bathroom. All exposure pathway formulas and parameters are displayed in Table 3. We adopted the weight of population pattern to calculate the concentration of THM species in the five regions of Taiwan. It is more reasonable to interpret the weight of population in the exposure concentration level. Utilized the concentration, it can obtain the CDI values from different exposure routes, respectively.

\subsubsection{Risk characterization}

In this step, the hazardous identification, dose-response and exposure assessment procedures are summarized and integrated into quantitative and qualitative expressions of the risk level. For carcinogenic effects, the risk is expressed as the probability that an individual will exhibit dose-response characteristics. Under the assumption that the slope factor is a constant, the risk related to the intake pathways in this study directly.

Linear low-dose cancer risk equation Risk $=\mathrm{CDI} \times \mathrm{SF}$,

where

Risk a unitless of an individual developing cancer,

CDI chronic daily intake averaged over 70 years $\left[\mathrm{mg}\left(\mathrm{kg} \mathrm{day}^{-1}\right)\right]$,

SF slope factor, expressed in milligram $\left(\mathrm{kg} \mathrm{day}^{-1}\right)$.

Estimating the risk or hazard potential requires a combination of simultaneous exposures to more than one pathway and carcinogenic effect. In this paper we assumed THM species dose are additivity. And there are no synergistic or antagonistic interactions. Equally, the total cancer risk assumes that all carcinogens are equal, and the slope factors derived from the animal data are given the same weights as factors derived from the human data. It can express into below:

Total exposure cancer risk $=$

Risk (exposure pathway 1)

+ Risk (exposure pathway 2)

$+\ldots+$ Risk (exposure pathway $i$ ) 


\subsubsection{Uncertainty and sensitivity analysis}

There are several types of uncertainty parameters. An important task in risk analysis is to determine what kinds of uncertainty are likely to affect the MCS finding suggested by USEPA (1997) in processing the uncertainty and sensitivity analysis. Essentially, MCS involves conducting and comparing repeated inputs that sample the system parameter distributions. This study utilized@Risk view (version 4.5) software to execute the data probability distribution and simulate the sensitivity using MCS. rectum and bladder cancers, respectively. Annual reports from the Department of Health, Taiwan (DOH http://www.doh.gov.tw/statistic/index.htm) announced the mean numbers for these cancers, which were discriminated by location from 1996 to 2000. Fig. 1 exhibited the ratio of death count versus water supply population (TWC http://www.water.gov.tw/samplel/ about/data1.asp\#3). The investigation results exhibited Northern region has a higher death count (colon $(1,535)$, rectum $(1,188)$ and bladder $(566))$, but Southern region displays higher ratio (colon $(0.15 \%)$, rectum $(0.14 \%)$ and bladder $(0.09 \%))$ in these cancers evidently.

\subsection{Statistic analysis of THMs species data}

Statistical results in Table 4 exhibit the means, maximum, minimum and standard deviations values in sub-
Fig. $2 \mathrm{BMD} / \mathrm{BMDL}$ values from a TCM, b BDCM, c DBCM and d TBM data by first stage multistage model fit with $95 \%$ confidence limits
TCM Multistage Model with 0.95 Confidence Level

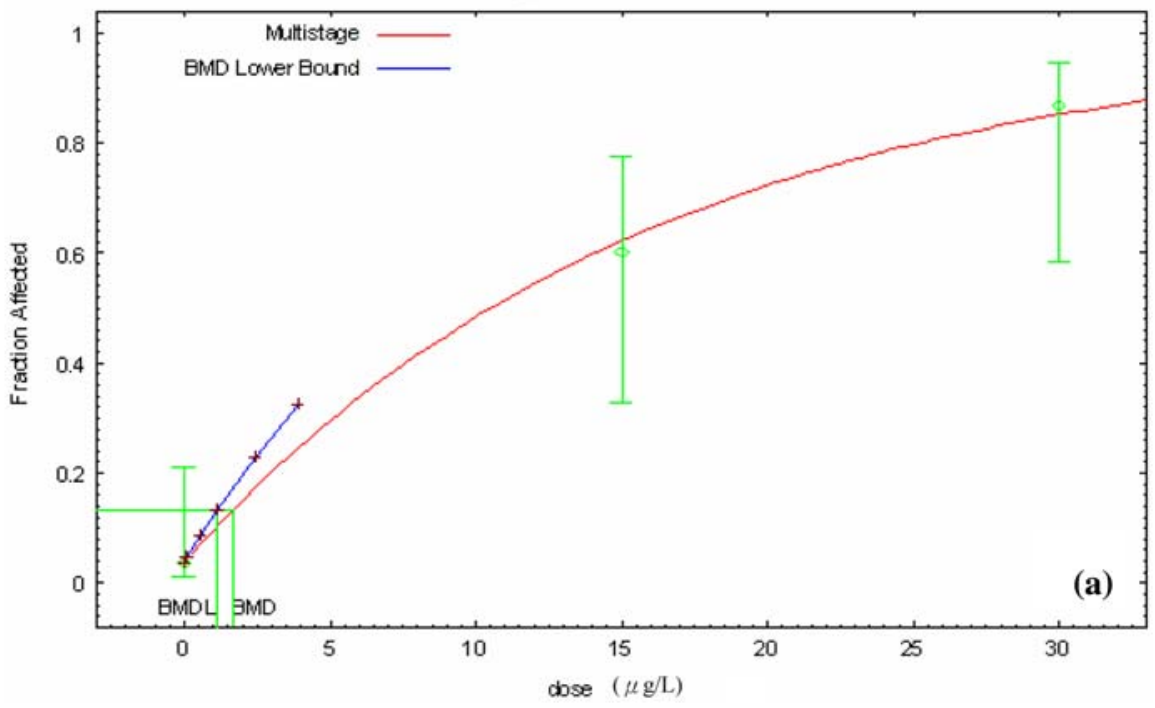

BDCM Multistage Model with 0.95 Confidence Level

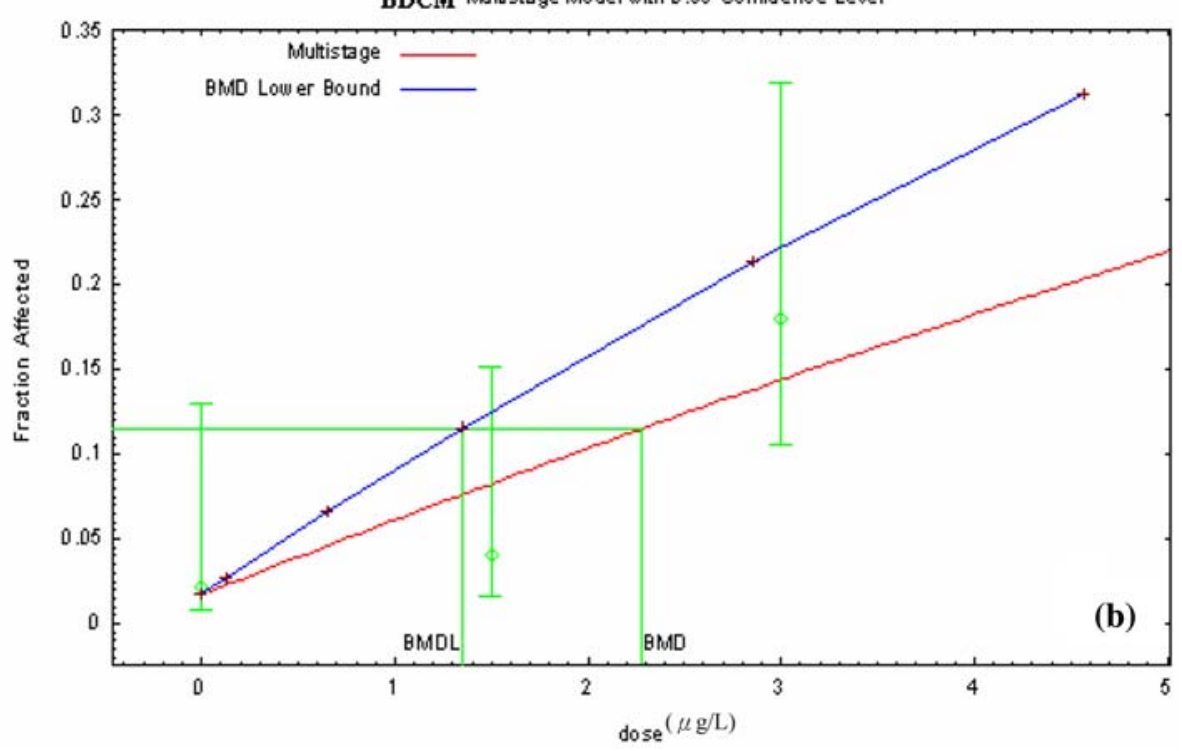


Fig. 2 (Contd.)
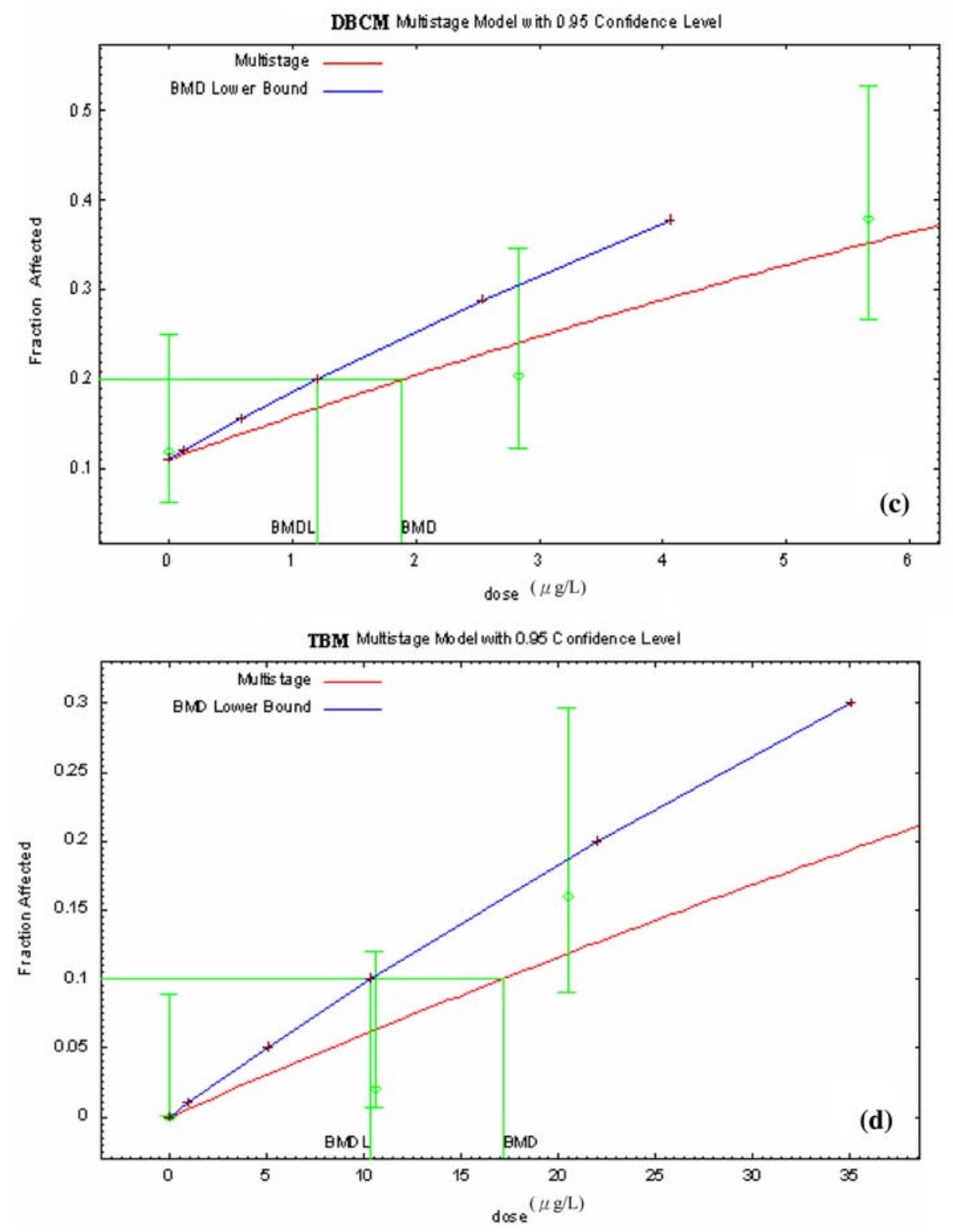

scriber levels. The TCM level is the predominant derivation of THMs in Taiwan. The Northern and Southern regions presented higher mean concentrations, shown by the epidemiology study investigation of Taiwan DOH.

In the BDCM, DBCM and TBM levels are predominant in external island. Previous research (GarciaVillanova et al. 1997; Golfinopoulos et al. 1996) verified groundwater and seawater contain bromide compounds if the water sources are near the seacoast. It conformed to the situation of external island of Taiwan.

\subsection{Hazard identification}

A number of epidemiological studies were performed to investigate adverse effects in human exposed to TCM, BDCM, DBCM and TBM, respectively.
Table 5 collates the physical-chemical properties, harmfulness, slope factors and quantity of Benchmark dose (BMD) of THMs species completely. Obviously, evidences of animal study revealed THMs species may carcinogenic hazardous materials.

\subsection{Dose-response assessment}

This study adopted a multistage type of benchmark model approved by USEPA (2003b) to process the doseresponse assessment. The chronic toxicity and carcinogenic potential of total THMs species at low dose situation were interpreted. Figure 2 shows the BMD/BMDL value for the total THMs species calculated from the Benchmark model from animal data $(95 \%$ confidence limits and first stage model fit). Furthermore, the range 
Fig. 3 MCS results of CDI values in the ingestion, inhalation, dermal intake exposure pathways and total risk probability distribution
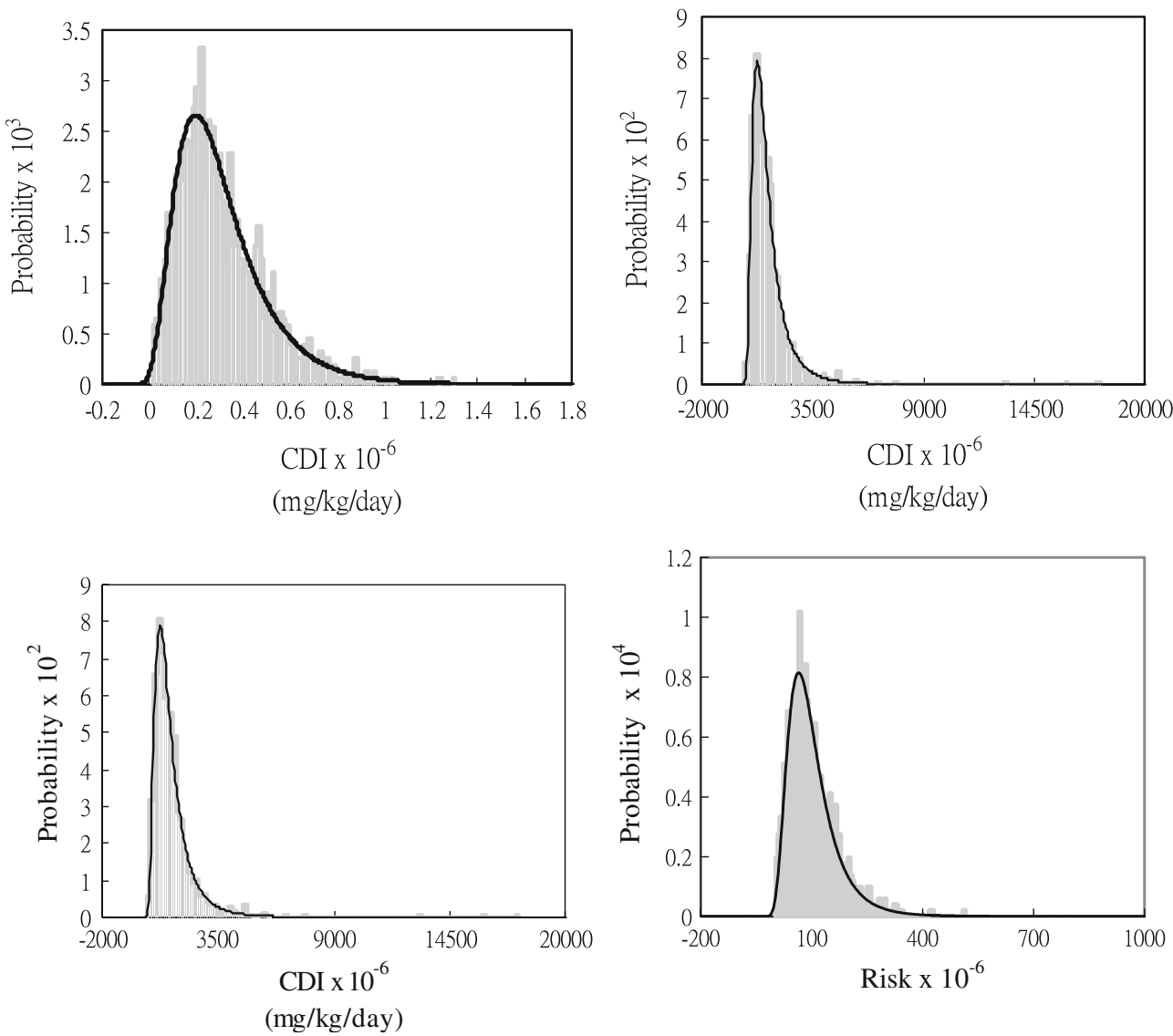

of BMD/BMDL value in first/second multistage model had shown in Table 5. Generally, the BMD values of first are higher than second stage, but the BMDL values are similar between first and second stage model. USEPA proposed the standard BMD and BMDL values of TCM is $1.69,1.15$; $\mathrm{BDCM}$ is $2.28,1.35$; $\mathrm{DBCM}$ is $1.88,1.20$; and BMD is $17.6,10.3 \mathrm{mg} / \mathrm{kg}$ day $^{-1}$, respectively.

\subsection{Exposure assessment}

THM species data processed the weighted average method via the regional population and specific year to acquire the statistical analysis. The MCS method was used to evaluate the CDI dose and obtain the probability distribution results by performing 1,000 frequency calculations.

Figure 3 shows the MCS consequence exhibited in the ingestion pathway, southern region exist the higher CDI values, in opposite to female examined higher CDI endured than male (CDI ranges are $1.07 \times 10^{-4}$ to $1.63 \times 10^{-3}$ and $9.22 \times 10^{-5}$ to $1.42 \times 10^{-3} \mathrm{mg}\left(\mathrm{kg} \mathrm{day}^{-1}\right)$, respectively). The variance in body weight between females and males is the main reason for the CDI ingestion level. Moreover, in the respired estimated, consequence exhibited in ingestion pathway, external island exist higher CDI values. Similarly, females exhibited higher levels than males (CDI range is $7.28 \times 10^{-6}$ to $1.42 \times 10^{-3} \mathrm{mg}\left(\mathrm{kg} \mathrm{day}^{-1}\right)$ and $4.29 \times 10^{-5}$ to
$4.96 \times 10^{-3} \mathrm{mg}\left(\mathrm{kg} \mathrm{day}^{-1}\right)$, respectively) because of their shower behavior. This included the difference between municipal and rural areas and gender. In the estimated skin contact, the dermal intake pathway was similar to the ingestion pathway. The Southern region exhibited higher CDI values and females were higher than males (CDI ranges are $2.55 \times 10^{-7}$ to $2.95 \times 10^{-5}$ and $2.42 \times 10^{-7}$ to $2.81 \times 10^{-5} \mathrm{mg}\left(\mathrm{kg} \mathrm{day}^{-1}\right)$, respectively). In the contact time during showers, females took longer showers than males. The Taiwan DOH announced and suggested that showers not exceed 12 minutes, otherwise, the health risk will increase.

\subsection{Risk characterization}

The THM species slope factor from the dose-response curve showed a low dose situation from the linear model (Table 5). Assumption the cancer risk is CDI multiplication slope factor and total cancer risks include different exposure pathways. The total cancer risk assessment order was southern, northern, central over the external island segment. The average value for females was $4.04 \times 10^{-6}$ to $4.67 \times 10^{-4}$ and $9.25 \times 10^{-6}$ to $4.07 \times 10^{-4}$ for men, respectively. Figures 4 and 5 exhibited the THM species distribution via different exposure pathways to estimate the CDI value, risk assessment and contribution percentage simultaneously. The cancer risk 
Fig. 4 Special distribution via different exposure pathways in CDI (a) and risk (b) assessment
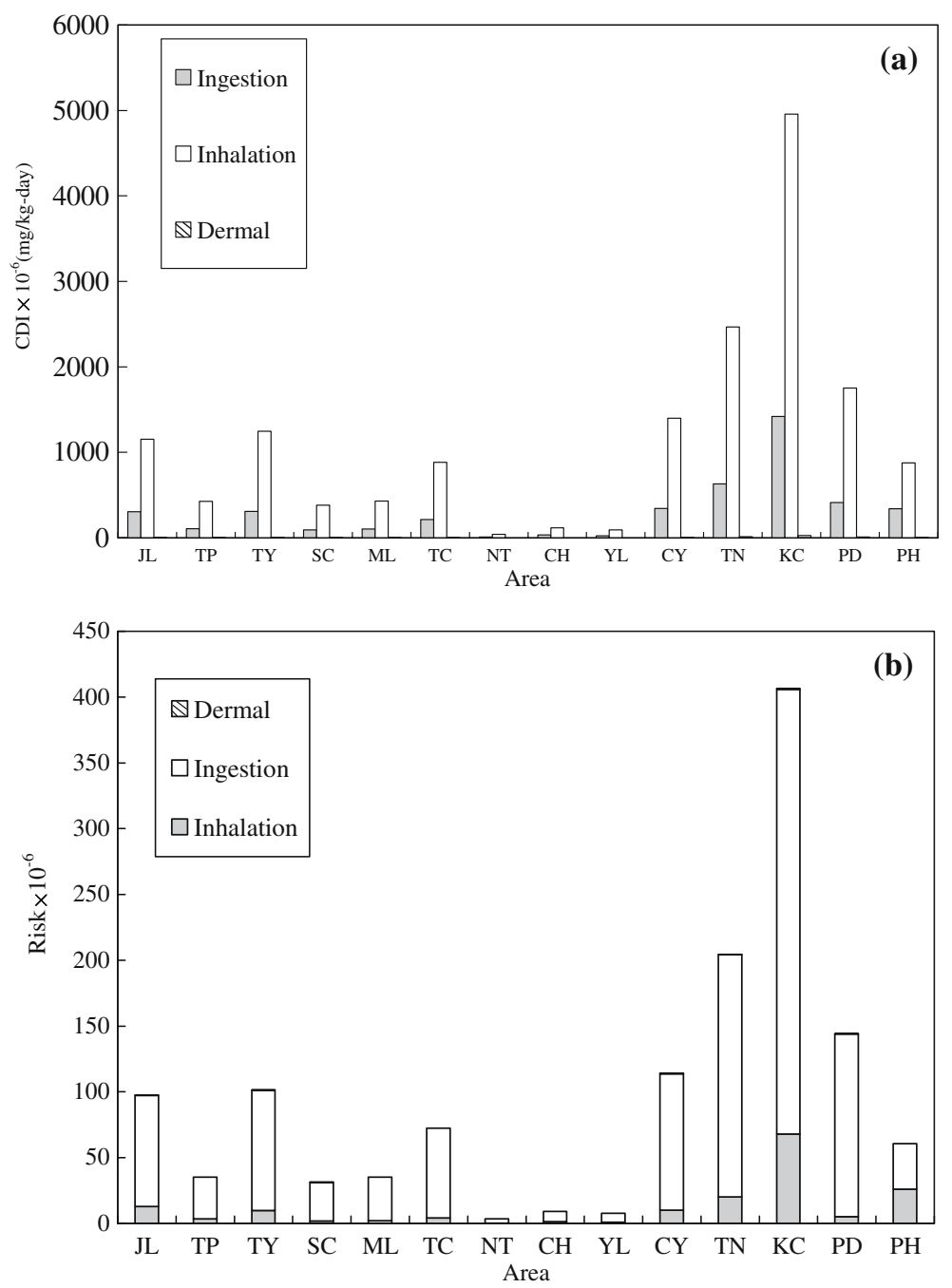

quantitative analysis evaluation for Taiwan (Arc View plot) is shown in Fig. 6. It is shown that the Southern Taiwan region presents a higher risk.

In term of the inhalation pathway distinct revealed the magnificent in the risk assessment of THMs species, continuous is ingestion and dermal intake pathways, respectively. TCM is the main contribution to the risk assessment in Taiwan (50\% approximately), and TBM is predominance in external island (50\% approximately).

\subsection{Sensitivity analysis}

The sensitivity analysis processed the $\pm 20 \%$ extra risk to interpret the effective THM species parameters, including body weight, intake quantity and exposure duration in formula of exposure assessment. Analysis was performed using the radar plots exhibited in Fig. 7. The research regions displayed a negative correlation consistent with the exposure duration and positive correlation in body weight dramatically. Furthermore, the TCM concentration is the predominant influence parameter in Taiwan, whereas the external islands are influenced by the DBCM concentration shown in Table 6.

\section{Conclusions}

In the mean concentration distribution of total THMs in Taiwan external islands $\left(48.39 \mu \mathrm{g} \mathrm{L}^{-1}\right)$, southern (17.28 $\left.\mu \mathrm{g} \mathrm{L}^{-1}\right)$, northern $\left(12.11 \mu \mathrm{g} \mathrm{L}^{-1}\right)$ and middle segments $\left(9.59 \mu \mathrm{g} \mathrm{L}^{-1}\right)$. By investigation consequences, the TCM concentration is the major DBP species in the local regions of Taiwan, and the external islands is characterized by TBMs, respectively.

A multistage Benchmark model (USEPA 2004) was used to evaluate the dose-response assessment. Consequence exhibited at the $95 \%$ confidence level, the BMD and the quantity of lower-bound confidence limit for the BMD (BMDL) of TCM were 1.69 and $1.15 \mathrm{mg}\left(\mathrm{kg} \mathrm{day}^{-1}\right)$, dibromochloromethane (DBCM) are 1.88 and $1.20 \mathrm{mg}\left(\mathrm{kg} \mathrm{day}^{-1}\right)$, dichloromethane (DCBM) are 2.28 and $1.35 \mathrm{mg}\left(\mathrm{kg} \mathrm{day}^{-1}\right)$ and TBM are 17.6 and $10.3 \mathrm{mg}\left(\mathrm{kg} \mathrm{day}^{-1}\right)$, respectively. The exposure was compared with the reaction dose concentration of 
Fig. 5 Different contribution percentage of THMs species and exposure pathways in cancer risk assessment $[(\mathbf{a})$ is male and (b) is female]
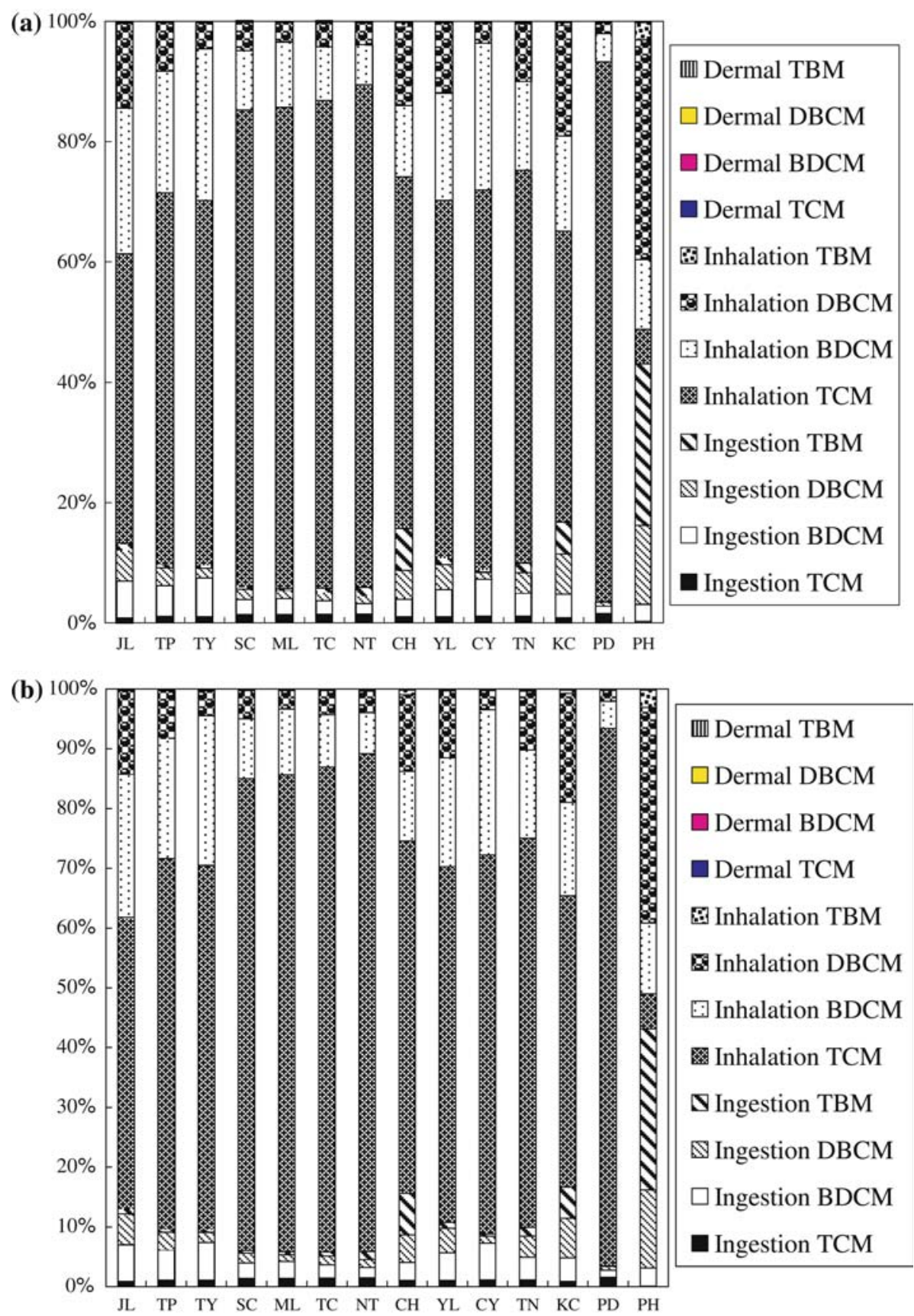

THMs species in drinking water. In terms of lower quantity of BMD/BMDL showed doses opposite to the cancer risk obviously.

In the exposure assessment calculated by MCS, inhalation was found as the principal pathway. The next pathway was ingestion followed by dermal intake. The quantity of average risk in male and female is $3.14 \times 10^{-5}$ to $1.04 \times 10^{-4}$ and $3.64 \times 10^{-5}$ to $1.16 \times 10^{-4}$ in northern, $9.25 \times 10^{-6}$ to $7.25 \times 10^{-5}$ and $4.04 \times 10^{-6}$ to $8.40 \times 10^{-5}$ in middle, $1.14 \times 10^{-4}$ to $4.07 \times 10^{-4}$ and $1.33 \times 10^{-4}$ to $4.67 \times 10^{-4}$ in southern, and $6.07 \times 10^{-5}$ and $7.09 \times 10^{-5}$ in external island, respectively. The Southern region presented a high cancer risk and corresponded with the result of epidemiology. Furthermore, females presented higher CDI values (intention risk level) than males in Taiwan.

Consequence of sensitivity analysis exhibited body weight and exposure duration are provided the influence in cancer risk analysis and assessment predominantly. Exposure time and body weight are the effective parameters used in the sensitivity analysis. The greater the exposure time, the greater the cancer risk endured. A negative correlation exists between body weight and the unit dose sustained risk probability.

Quantifying the risk factors is important for population and decision-making policy for drinking water 
Fig. 6 Quantity of cancer risk assessment of Taiwan (Arc View plot)

Table 6 Cancer risk assessment sensitivity analysis

Numbers exhibited are the extent of sensitivity, and 1 is the most sensitivity

$B W$ Body weight, $I R$ intake quantity, ET exposure time

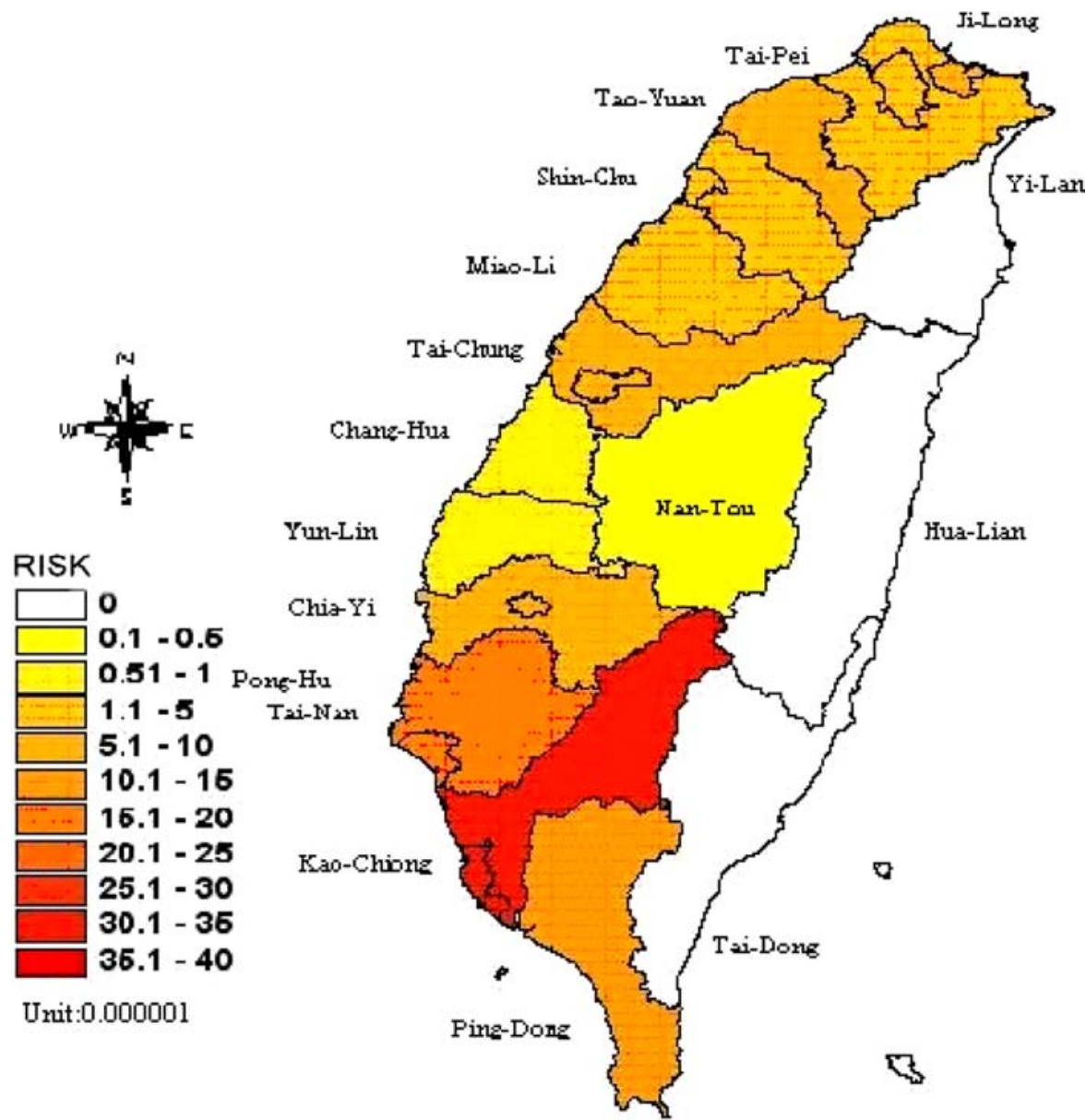

\begin{tabular}{lllllllll}
\hline Regions & Parameters & TCM & BDCM & DBCM & TBM & BW & IR & ET \\
\hline \multirow{2}{*}{ Northern } & Ji-Long & 3 & 4 & 5 & 7 & 1 & 6 & 2 \\
& Tai-Pei & 3 & 4 & 5 & 6 & 1 & 5 & 2 \\
& Tao-Yuan & 3 & 4 & 6 & 6 & 1 & 5 & 2 \\
\multirow{5}{*}{ Middle } & Shin-Chu & 3 & 4 & 5 & 6 & 1 & 5 & 2 \\
& Miao-Li & 3 & 4 & 6 & 7 & 1 & 5 & 2 \\
& Tai-Chung & 3 & 4 & 5 & 6 & 1 & 5 & 2 \\
& Nan-Tou & 3 & 4 & 6 & 7 & 1 & 5 & 2 \\
\multirow{5}{*}{ Southern } & Chang-Hua & 3 & 6 & 4 & 7 & 1 & 5 & 2 \\
& Yun-Lin & 3 & 4 & 5 & 7 & 1 & 6 & 2 \\
& Chia-Yi & 3 & 4 & 6 & 7 & 1 & 5 & 2 \\
\multirow{3}{*}{ External island } & Tai-Nan & 3 & 4 & 5 & 7 & 1 & 6 & 2 \\
& Kao-Chiong & 3 & 5 & 4 & 7 & 1 & 6 & 2 \\
& Ping-Dong & 3 & 4 & 5 & 7 & 1 & 6 & 2 \\
& Peng-Hu & 7 & 6 & 3 & 5 & 1 & 4 & 2
\end{tabular}

Table 7 Legislation limit values for different counties in DBPs level

\begin{tabular}{|c|c|c|c|c|c|c|}
\hline Chemicals & Taiwan & USA & WHO & Japan & Sweden & Australia \\
\hline DBCM & - & - & 0.10 & 0.03 & - & - \\
\hline TBM & - & - & 0.10 & 0.09 & - & - \\
\hline Total THMs species & 0.10 & Stage one: reduced to 0.08 ; Stage two: reduced to 0.04 & $1.0(\mathrm{mg} / \mathrm{L})^{a}$ & 0.10 & 0.05 & 0.25 \\
\hline Trichloroacetic acid & - & - & 0.10 & 0.3 & - & 0.10 \\
\hline Dichloroacetic acid & - & - & 0.05 & 0.04 & - & 0.10 \\
\hline
\end{tabular}

${ }^{a}$ Mean THMs ratio 

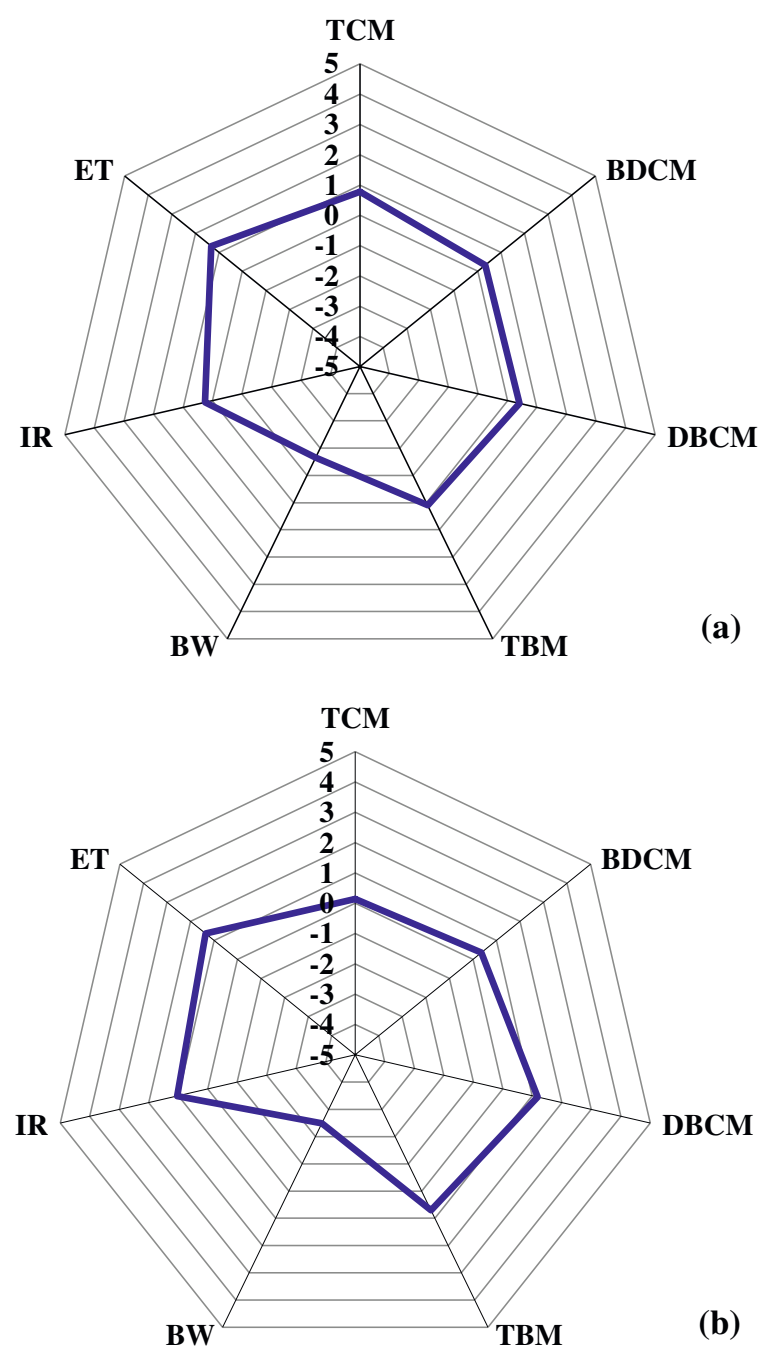

Fig. 7 Radar plots for sensitivity analysis in Taiwan area (a) and external island (b)

safety. Fortunately, the Benchmark model and MCS @ Risk supply the methodology were used for risk calculation. The standard for the total THMs species in Taiwan was $100 \mathrm{ppb}$ presently. Table 7 displays the legislation limit values for different countries for DBPs levels. We suggest that the standard be separated using separate TCM, BDCM, DBCM and TBM standards. This may establish a control management for individual material to reduce the harmful risk.

Acknowledgements The authors gratefully acknowledge the fund support by National Science Council (NSC-93-2621-Z-035-002)and the assistance of the Taiwan Water Corporation in this study.

\section{References}

Bellar TA, Lichtenberg JJ, Kroner RC (1974) The occurrence of organohalides in chlorinated drinking waters. J Am Water Works Assoc 66:703-706
Bove FJ, Fulcomer MC, Klotz JB, Esmart J, Dufficy EM, Savrin JE (1995) Public drinking water contamination birth outcome. Am J Epidemiol 141:850-862

Cantor KP, Hoover R, Mason TJ, McCabe LJ (1978) Association of cancer mortality with halomethanes in drinking water. J Natl Cancer Inst 61:979-985

Cantor KP, Hoover R, Hartge P (1987) Bladder cancer, drinking water sources, and tap water consumption: a case control study. J Natl Cancer Inst 79:1269-1279

Cantor KP, Lynch CF, Hildesheim ME, Dosemeci M, Lubin J, Alavanja M, Craun G (1998) Drinking water source and chlorination byproducts I Risk of bladder cancer. Epidemiology $9: 21-28$

Chen WM (2003) Health risk analysis and assessment of trihalomethanes in drinking water of Taiwan, Master Thesis, Feng Chia University

Dan YJ (2003) Formation and risk assessment of trihalomethanes in drinking water, Master Thesis, National Taiwan University

Doyle TJ, Zheng W, Cerhan JR, Hong CP, Sellers TA, Kushi LH, Polsom AR (1997) The association of drinking water source and chlorination by-products with cancer incidence among postmenopausal women in Iowa: a prospective cohort study. Am J Public Health 87:1168-1176

Garcia-Villanova RJ, Garcia C, Gomez JA, Garcia MP, Ardanny $\mathrm{R}$ (1997) Formation, evolution and modeling of trihalomethanes in the drinking water of a town: at the muncipal treatment utilities. Water Res 31:1299-1308

Gallagher MD, Nuckols JR, Stallones L, Savitz DA (1998) Exposure to trihalomethanes and adverse pregnancy outcomes. Epidemiology 9:484-489

Golfinopoulos SK, Kostopoulou MN, Lekkas TD (1996) THMs formation in the high bromide water supply of Athens. J Environ Sci Health A 31:67-81

Heywood R, Sortwell RJ, Noel PRB (1979) Safety evaluation of toothpaste containing chloroform: III. Long-term study in beagle dogs. J Environ Pathol Toxicol 2:835-851

Hossein P, Stevens AA (1995) Relationship between trihalomethanes and haloacetic acids with total organic halogen during chlorination 29:2059-2062

Houston AC (1913) Studies in water supply. Macmillan \& Co, London

Hsu CH, Jeng WL, Chang RM, Chien LC, Han BC (2001) Estimation of potential lifetime cancer risk for trihalomethanes from consuming chlorinated drink water in Taiwan. Environ Res 85:77-82

Jo WK, Weisel CP, Lioy PJ (1990) Routes of chloroform exposures and body burden from showering with chlorinated tap water. Risk Anal 10:575-580

Kramer MD, Lynch CF, Isacson P, Hanson JW (1992) The association of waterborne chloroform with intrauterine growth retardation. Epidemiology 3:407-413

Lee SC, Guo H, Lam SMJ, Lau SLA (2004) Multipathway risk assessment on disinfection by-products of drinking water in Hong Kong. 94:47-56

Lin TF, Hoang SW (2000) Inhalation exposure to THMs from drinking water in south Taiwan. Sci Total Environ 246:41-49

Little, John C (1992) Applying the two-resistance theory to contaminant volatilization in showers. Environ Sci Technol 26:1341-1349

Maxwell NI, Burmaster DE, Ozonoff D (1991) Trihalomethanes andmaximum contaminant levels: the significance of inhalation and dermal exposures to chloroform in household water. Regul Toxicol Pharmacol 14:297-312

MCKone TE (1989) Household exposure models. Toxicol Lett 49:321-339

Morris RD, Audet AM, Angelillo IF, Chalmers TC, Mosteller F (1992) Chlorination, chlorination by-products, and cancer: a meta-analysis. Am J Public Health 82:955-963

National Research Council (1983) Risk assessment in the federal government: managing the process. NAS Press, Washington 
National Toxicology Program (NTP) (1985) Toxicology and carcinogenesis studies of chlorodibromomethane (CAS. No. 124$48-1$ ) in $\mathrm{F} 344 / \mathrm{N}$ rats and B6C3F1 mice (gavage studies). National Toxicology Program Technical Report Series No. 282. DHHS Publications No. (NIH), 85-2538

National Toxicology Program (NTP) (1987) Toxicology and carcinogenesis studies of bromodichloromethane (CAS. No. 75$27-4$ ) in $\mathrm{F} 344 / \mathrm{N}$ rats and B6C3F1 mice (gavage studies). National Toxicology Program Technical Report Series No. 321. DHHS Publications No. (NIH), 85-2537

National Toxicology Program (NTP) (1988) Toxicology and carcinogenesis studies of bromoform (CAS. No. 75-25-2) in F344/N

Page T, Harris RH, Epstein SS (1976) Drinking water and cancer mortality in Louisiana. Science 193:55-57

Rook JJ (1974) Formation of haloforms during chlorination of natural water. Water Treat Exam 23:234-243

U.S. Environmental Protection Agency (USEPA) (2004) The Benchmark Dose Software 1.3.2. Available on the Internet at: http://www.epa.gov/ncea

U.S. Environmental Protection Agency (USEPA) (1989) Risk assessment guidance for superfund. USEPA, Washington DC

U.S. Environmental Protection Agency (USEPA) (1997) Exposure factors handbook. USEPA, Washington DC

USEPA (1986) Guidelines for carcinogen risk assessment. U.S. Environmental Protection Agency, Washington DC. EPA/600/ 8-87/045

USEPA (1999) Guidelines for carcinogen risk assessment. Risk Assessment Forum, U.S. Environmental Protection Agency, Washington DC. NCEA-F-0644

USEPA (2002) Integrated risk information system (electronic data base). U.S. Environmental Protection Agency, Washington DC. Available on Internet at: http://www.epa.gov/iris

USEPA (2003a) Risk assessment information system (electronic data base). U.S. Environmental Protection Agency, Washington DC. Available on Internet at: http://www.cfpub.epa.gov/ iris Cited Aug 2003.
USEPA (2003b) The Benchmark Dose Software 1.3.2. EPA NCEA. Available on Internet at:http://www.epa.gov/ncea

Waller K, Swan SH, DeLorenze G, Hopkins B (1998) Trihalomethanes in drinking water and spontaneous abortion. Epidemiology 9:134-140

Wang KS, Dan YJ (2003) Health risk assessment and distribution of trihalomethanes in drinking water of Taiwan. In: Twentyfirst conference, Taiwan Water Cooperation

Weisel CP, Jo WK (1996) Ingestion, inhalation and dermal exposure to chloroform andtrichlor oethene from tap water. Environ Health Perspect 104:48-51

Weisel CP, Kim H, Haltmeier P, Klotz JB (1999) Exposure estimates to disinfection by-products of chlorinated drinking water. Environ Health Perspect 107:103-110

Wu KY (1999) Applicated toxicological mechanism in the risk assessment (in Chinese). Taiwan National Science Council report (NSC 89-2621-Z-039-001)

Wu KY, Chen MJ, Chang L (2003) A new approach to estimate the volatilization rates of volatile organic compounds during showering. Atmos Environ 37:4325-4333

Yang CY, Chiu JF, Chiu HF, Wang TN, Lee CH, Ko YC (1996) Relationship between water hardness and coronary mortality in Taiwan. J Toxicol Environ Health 49:1-9

Yang CY, Chiu HF, Cheng MF, Tsai SS (1998) Chlorination of drinking water and cancer mortality in Taiwan. Environ Res 78:1-6

Yang CY, Cheng BH, Tsai SS, Wu TN, Lin MC, Lin KC (2000) Association between chlorination of drinking water and adverse pregnancy outcome in Taiwan. Environ Health Perspect 108:765-768 